\title{
Experimental study of zone of yield strength on corroded construction steel specimens for reuse
}

\author{
Antonio Shopov ${ }^{1, *}$, and Borislav Bonev ${ }^{2}$ \\ ${ }^{1}$ Technical University of Sofia, "Strength of materials" Department, 8 Kl. Ohridski blvd. 1000 Sofia, \\ Bulgaria \\ ${ }^{2}$ Technical University of Sofia, "Microelectronics" Department, 8 Kl. Ohridski blvd. 1000 Sofia, \\ Bulgaria
}

\begin{abstract}
Zone of yield strength is a part of stress-strain diagram on steel. In this zone is located an upper and lower yield strength points. These points are important for calculation and design of steel structures elements. When a structural element is corroded, its mechanical properties are changed i.e. changes the geometric characteristics, superficial defects appear and leads to structural changes of material. The facts unambiguously determine that in order to decide whether or not the corrosion element can be reuse, it is necessary to study the material and to determine the new values at the yield strength points. In order to legally make the necessary calculation in sizing and to judge for its reuse. The report studies a zone of yield strength on steel elements with corrosion. Experimental data was obtained, then processed using the stochastic method of processing empirically obtained data, and it was determined with sufficient probability the values to be used for calculation and design in practice.
\end{abstract}

\section{Introduction}

The technology of steel production determines a yield strength zone, strength properties, chemical composition and others. One of the main challenges during the operation of a steel structural element is corrosion. Although most steel elements have some anti-corrosion protection over time, this protection is weakened and the appearance of corrosion becomes inevitable. Corrosion has a negative impact on mechanical properties, geometric characteristics of the cross-section, surface defects, structural changes and etc. [1]. Once corrosion occurs, it can not be guaranteed that the calculations made in the design are sufficiently reliable and accurate. Although regulatory norms are in place, it is in the interest of security to carry out a further check. In some countries around the world (Bulgaria, for example) there is a possibility of using recycled materials with a view to their reuse in non-significant structural elements. This opportunity should not be missed and ways to reuse the corroded steel element into a relevant element when proving the

\footnotetext{
*Corresponding author: ansh@tu-sofia.bg
} 
normative requirements. In order to realize this possibility, a re-calculation should be performed with the changed values in yield strength zone, which values are involved in the calculation and design of the elements.
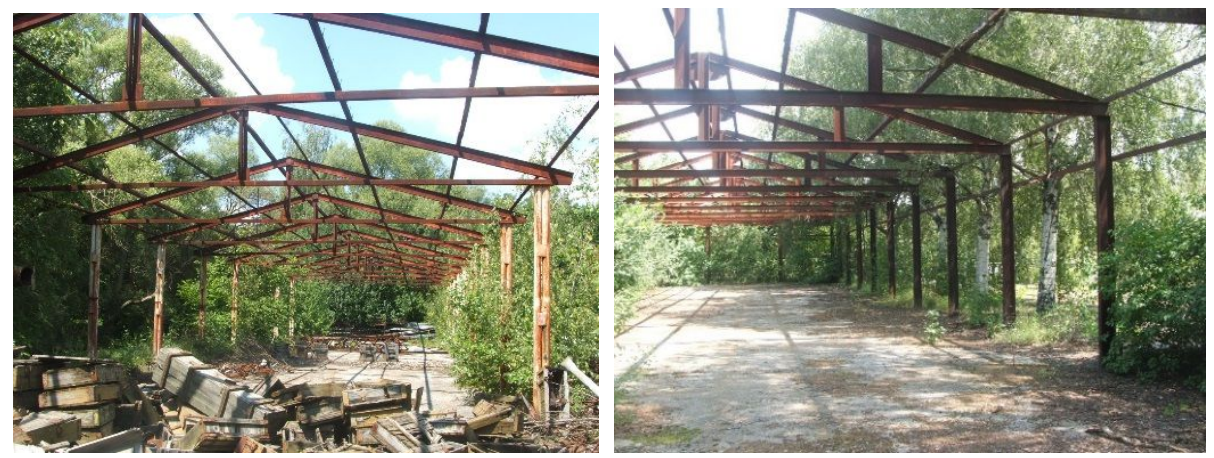

Fig. 1. Corroded steel structures which elements may using again.

\section{Accelerated corrosion method for experiment}

There are many ways and standards for obtaining accelerated corrosion, which by its very nature is artificially caused. We will use a galvanostatic method, as do other researchers [27]. The acceleration of the corrosion process is accomplished by using an external source of direct current and anodic dissolution of the steel. The test sample is connected to the positive pole of the source (anode). A stainless-steel plate or other inert metal is connected to the negative pole (cathode). In [3] the desired loss of mass $\eta$ is $2 \div 80 \%$. It is achieved by applying a constant current $\mathrm{I}[\mathrm{A}]$ for a time period $\mathrm{t}$ [s] defined by the Faraday law:

$$
t=\frac{\eta W z F}{M I} ; \quad I=A \times J
$$

where $\mathrm{W}[\mathrm{g}]$ is the weight of the original steel wire, $\mathrm{z}$ is the valence of the ion $(\mathrm{z}=2,5$ is the average value for $\mathrm{Fe}^{2+}$ and $\mathrm{Fe}^{3+}$ ions of the corrosion products), $\mathrm{F}=96484 \mathrm{C} / \mathrm{mol}$ is the Faraday constant, $\mathrm{M}=56 \mathrm{~g} / \mathrm{mol}$ is the atomic mass of the ferric-Ion, $\mathrm{A}\left[\mathrm{cm}^{2}\right]$ is the surface area, $\mathrm{J}$ is current density $\left[\mathrm{A} / \mathrm{cm}^{2}\right]$.

A stabilized current is given for a certain amount of time to achieve a certain degree of corrosion. The used electrolyte is solution of $5 \% \mathrm{NaCl}$. Current of $400 \mathrm{~mA}$ for 7 steel specimens (group A) is used and current of $200 \mathrm{~mA}$ for another 7 steel specimens (group B) is used.

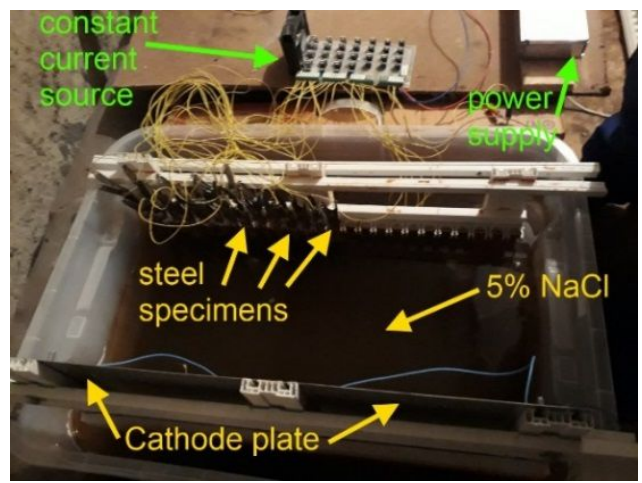

Fig. 2. The used experimental set-up. 


\section{Construction steel specimens}

The choice of dimensions of the test specimen depends on a number of factors. Depending on the standard and the test method, the dimensions of the test specimen also depend. In Bulgaria, the most commonly used structural steel for constructions is S355JR.

Table 1. Chemical composition on steel specimens.

\begin{tabular}{|c|c|c|c|c|c|c|c|c|c|c|}
\hline \multicolumn{10}{|c|}{ Chemical composition, [\%] } \\
\hline $\mathbf{F e}$ & $\mathbf{C}$ & $\mathbf{S i}$ & $\mathbf{M n}$ & $\mathbf{P}$ & $\mathbf{S}$ & $\mathbf{C u}$ & $\mathbf{N}$ & $\mathbf{N i}$ & $\mathbf{A s}$ & $\mathbf{C r}$ \\
\hline 96.4 & 0.24 & 0.55 & 1.6 & 0.04 & 0.04 & 0.55 & 0.01 & 0.27 & 0.07 & 0.29 \\
\hline
\end{tabular}

Our test specimens will be tensile tested according to ISO 6892-1:2016, which means they must meet the requirements of this standard. In standard are given the minimum dimensions of a test steel specimen. Some authors recommend that the parallel length is $15 \mathrm{~d}$ [8], saying that the best and most reliable results are obtained right then. Using these considerations, we take the dimensions of the test specimens.

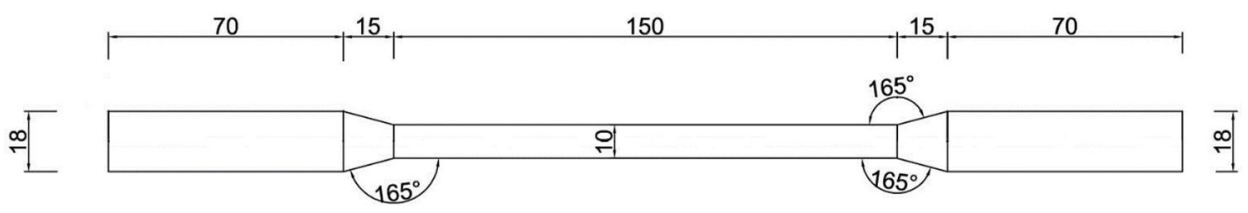

Fig. 3. Dimensions of steel specimens.

We have 18 steel specimens. One of them is a control specimen. Another 3 of them we tested without corrosion and 14 steel specimens we make a corroded according galvanostatic method - group A and group B.
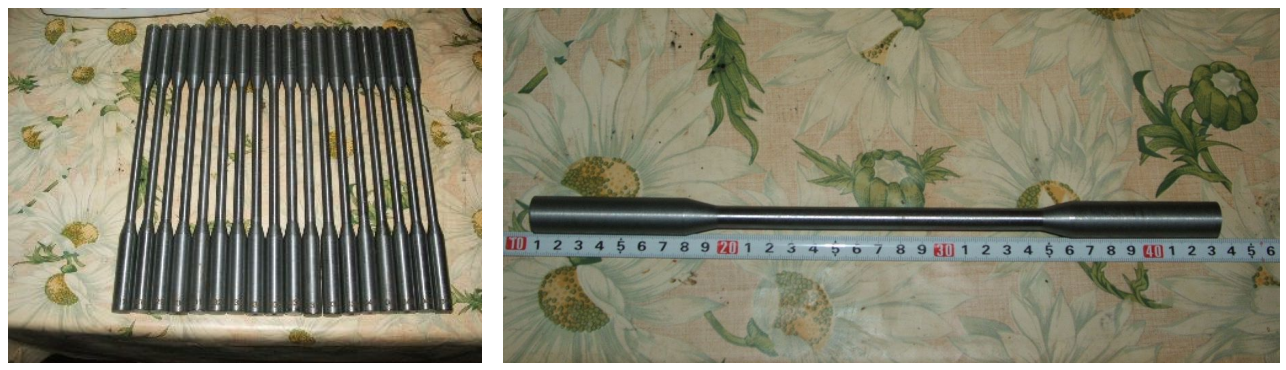

Fig. 4. Steel specimens for experiment.

\section{Results}

Our steel specimens are tested on universal testing machine MESSPHYSIK model BETA200-7/6x14. Before we to do test our specimens, we remove corrosion products (rust) of them according standard ISO 8407:2009 in hydrochloric acid (10 min, in solution of 500 $\mathrm{ml}$ hydrochloric acid with $1000 \mathrm{ml}$ distilled water and $3.5 \mathrm{~g}$ hexamethylenetetramine on temperature $20^{\circ} \mathrm{C}$ ). We use the stochastic method to process the obtained empirical data, as these are random variables [9]. 
Table 2. Results of 3 non-corroded steel specimens (tensile tested).

\begin{tabular}{|c|c|c|c|c|c|c|c|}
\hline \multirow{2}{*}{$\begin{array}{c}\text { No of } \\
\text { steel } \\
\text { specimen }\end{array}$} & Area & \multicolumn{2}{|c|}{$\begin{array}{c}\text { lower yield } \\
\text { strength (point) }\end{array}$} & \multicolumn{2}{c|}{$\begin{array}{c}\text { upper yield } \\
\text { strength (point) }\end{array}$} & \multicolumn{2}{|c|}{ tensile strength } \\
\cline { 2 - 8 } & $\begin{array}{c}\mathbf{A} \\
{\left[\mathbf{m m}^{2}\right]}\end{array}$ & $\begin{array}{c}\text { Disp. } \\
{[\mathbf{m m}]}\end{array}$ & $\begin{array}{c}\text { Rmin } \\
{[\mathbf{M P a}]}\end{array}$ & $\begin{array}{c}\text { Disp. } \\
{[\mathbf{m m}]}\end{array}$ & $\begin{array}{c}\text { Rmax } \\
{[\mathbf{M P a}]}\end{array}$ & $\begin{array}{c}\text { Disp. } \\
{[\mathbf{m m}]}\end{array}$ & $\begin{array}{c}\text { Rm } \\
{[\mathbf{M P a}]}\end{array}$ \\
\hline 1 & 78.23 & 8.44 & 324.08 & 5.28 & 362.89 & 32.00 & 436.60 \\
\hline 2 & 78.23 & 4.72 & 324.30 & 2.63 & 364.80 & 30.13 & 445.10 \\
\hline 3 & 78.23 & 4.89 & 304.71 & 2.70 & 334.84 & 31.02 & 445.90 \\
\hline
\end{tabular}

Where: Rmin is a minimum of stress in yield strength zone, Rmax is a maximum of stress in yield strength zone, Disp. is a displacement, $\mathrm{Rm}$ is a tensile strength, $\mathrm{A}$ is area of cross-section
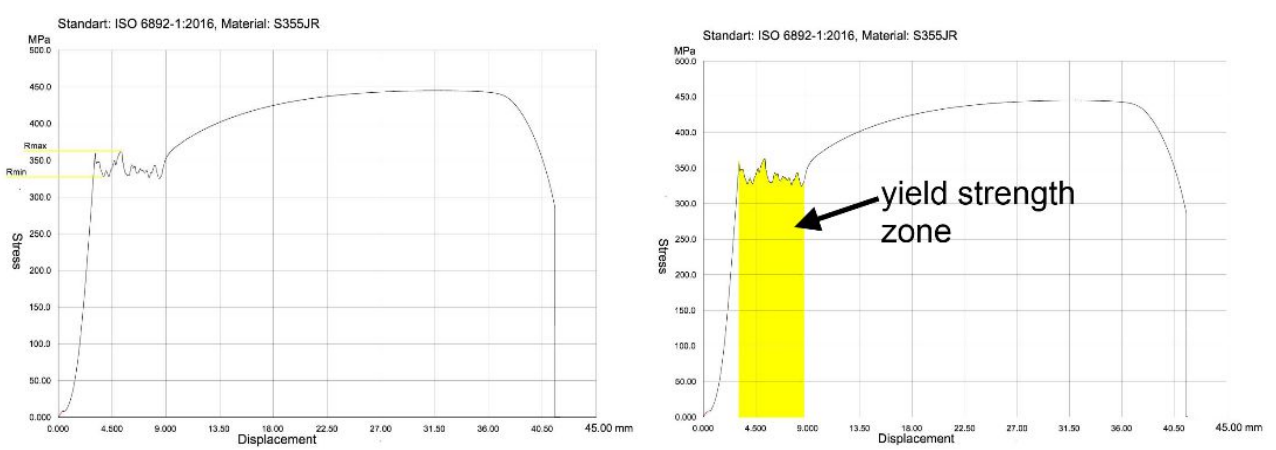

Fig. 5. Stress-displacement diagram on non-corroded specimen - zone of yield strength.
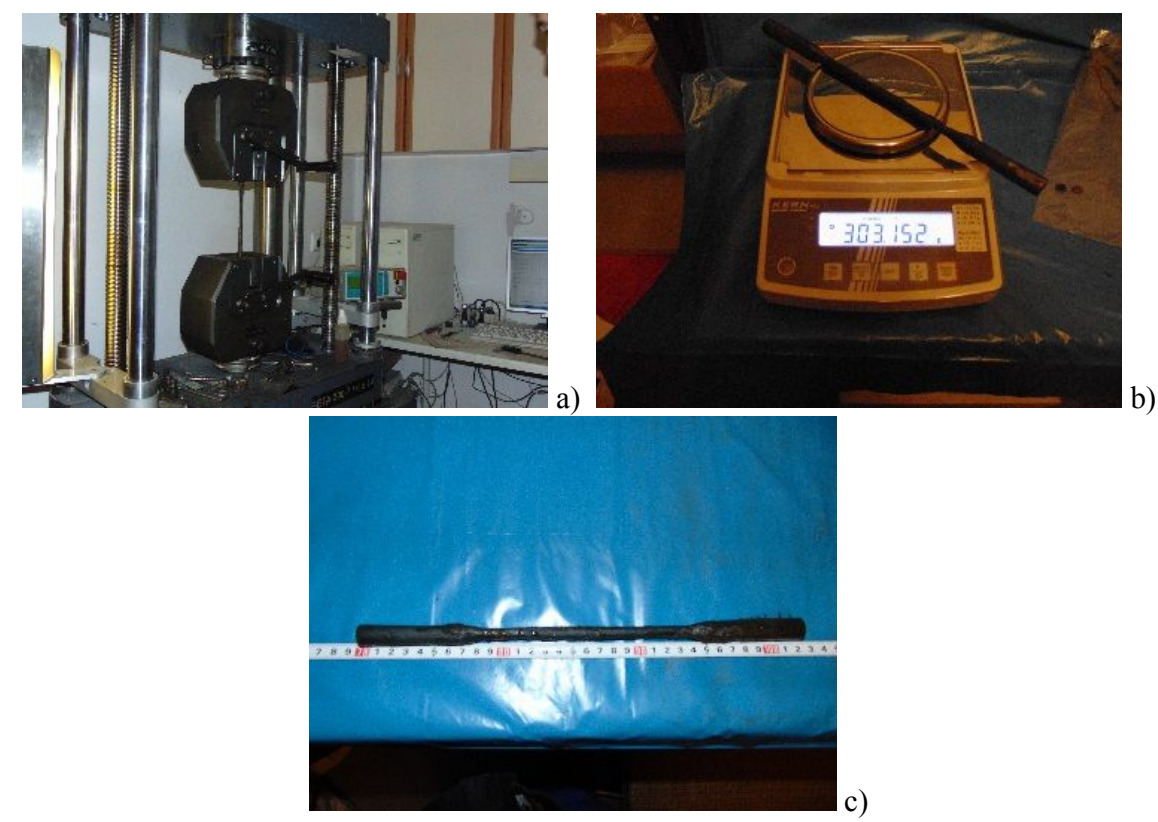

Fig. 6. Moments of experiment - a) tensile strength testing; b) measurement of corroded steel specimen; c) steel specimen after remove corrosion products (rust). 
Table 3. Results of 14 corroded steel specimens (tensile tested).

\begin{tabular}{|c|c|c|c|c|c|c|c|}
\hline \multirow{2}{*}{$\begin{array}{l}\text { № of steel } \\
\text { specimen }\end{array}$} & \multirow{2}{*}{ 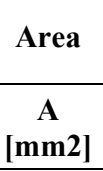 } & \multicolumn{2}{|c|}{$\begin{array}{c}\text { lower yield } \\
\text { strength (point) }\end{array}$} & \multicolumn{2}{|c|}{$\begin{array}{c}\text { upper yield } \\
\text { strength (point) }\end{array}$} & \multicolumn{2}{|c|}{ tensile strength } \\
\hline & & $\begin{array}{l}\text { Disp. } \\
{[\mathrm{mm}]}\end{array}$ & $\begin{array}{l}\text { Rmin } \\
\text { [MPa] }\end{array}$ & $\begin{array}{l}\text { Disp. } \\
{[\mathrm{mm}]}\end{array}$ & $\begin{array}{l}\text { Rmax } \\
\text { [MPa] }\end{array}$ & $\begin{array}{l}\text { Disp. } \\
{[\mathrm{mm}]}\end{array}$ & $\begin{array}{c}\mathbf{R m} \\
{[\mathrm{MPa}]}\end{array}$ \\
\hline \multicolumn{8}{|c|}{ Group A } \\
\hline 4 & 27.15 & 8.12 & 304.93 & 7.69 & 381.30 & 21.05 & 448.00 \\
\hline 5 & 18.25 & 4.24 & 341.61 & 8.72 & 408.62 & 13.37 & 441.40 \\
\hline 6 & 18.86 & 3.01 & 311.49 & 5.75 & 401.99 & 13.60 & 450.50 \\
\hline 7 & 17.35 & 3.55 & 320.70 & 7.65 & 437.92 & 12.71 & 461.00 \\
\hline 8 & 16.47 & 3.23 & 305.97 & 8.02 & 398.38 & 15.89 & 440.90 \\
\hline 9 & 19.01 & 2.39 & 305.82 & 5.48 & 376.15 & 15.87 & 429.00 \\
\hline 10 & 19.56 & 3.79 & 322.61 & 7.64 & 400.00 & 11.69 & 446.00 \\
\hline $\begin{array}{l}\text { average } \\
\text { results }\end{array}$ & 19.52 & 4.05 & 316.16 & 7.28 & 400.62 & 14.88 & 445.26 \\
\hline $\begin{array}{l}\text { stochastic } \\
\text { result }\end{array}$ & 20.30 & 4.34 & 320.01 & 8.18 & 407.66 & 15.60 & 450.21 \\
\hline \multicolumn{8}{|c|}{ Group B } \\
\hline 11 & 39.82 & 2.83 & 338.15 & 7.31 & 448.46 & 14.54 & 477.50 \\
\hline 12 & 47.42 & 3.67 & 322.09 & 5.12 & 366.87 & 17.72 & 443.90 \\
\hline 13 & 44.65 & 3.43 & 329.90 & 8.11 & 390.65 & 20.48 & 464.10 \\
\hline 14 & 45.36 & 3.97 & 350.22 & 8.66 & 389.10 & 24.54 & 488.40 \\
\hline 15 & 42.54 & 3.30 & 356.56 & 6.56 & 418.41 & 17.11 & 483.00 \\
\hline 16 & 43.36 & 4.33 & 356.19 & 7.92 & 379.60 & 19.83 & 476.60 \\
\hline 17 & 51.40 & 3.82 & 325.04 & 7.18 & 370.85 & 23.17 & 466.30 \\
\hline $\begin{array}{c}\text { average } \\
\text { results }\end{array}$ & 44.94 & 3.62 & 339.73 & 7.27 & 394.85 & 19.62 & 471.40 \\
\hline $\begin{array}{l}\text { stochastic } \\
\text { result }\end{array}$ & 44.94 & 3.38 & 344.08 & 7.62 & 407.66 & 20.03 & 473.82 \\
\hline
\end{tabular}
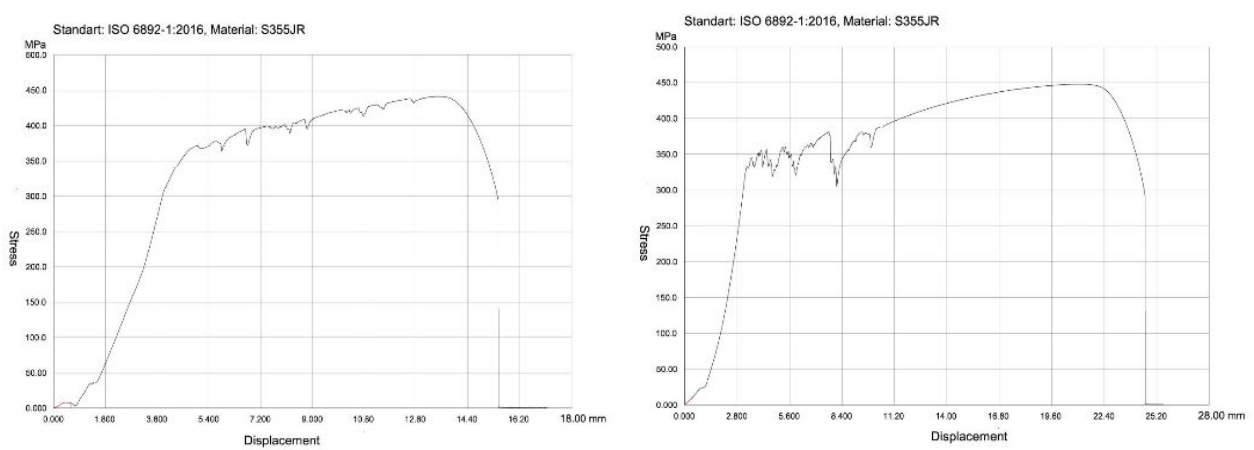

Fig. 7. Stress-displacement diagram on corroded specimens - group A. 

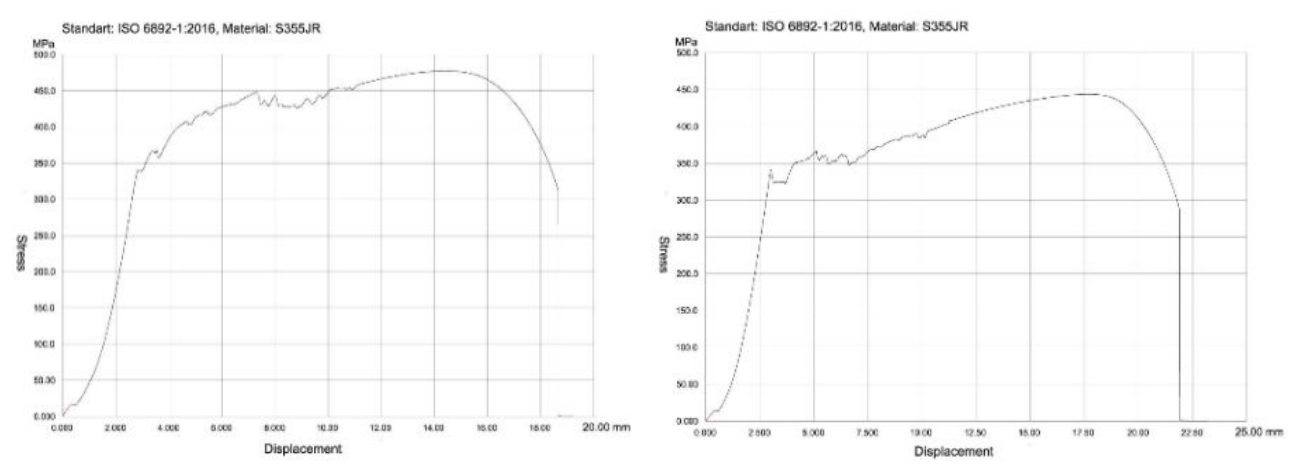

Fig. 8. Stress-displacement diagram on corroded specimens - group B.

\section{Conclusion}

The obtained results unequivocally find that there is probably a correlation between the development of corrosion and the strength of steel. The search for formula and / or dependence should be continued in order to determine the development of strength in corroded steel structures. Since the diagrams and the processing of the obtained results unequivocally show that corrosion strengthening of the steel is a fact. This fact should be used in the calculation and design of such elements for re-use, but further investigation should be carried out at which point the corrosion strengthening appears and can be relied upon.

Interestingly, the chart starts to change and yield strength zone almost disappears

Reuse hides its risks and should be approached by experimentally proving the strength properties of the corroded material. The experiment found that under certain conditions it was possible to re-use corroded steel elements in the construction.

\section{References}

1. A. Shopov, R. Ganev, Annual of UACEG, 51, 10 (Bulgarian, 2018)

2. A. Shopov, B. Bonev, N. Brayanov, CETRA 2018 book of proceedings "Road and Rail Infrastructure $V^{\prime \prime}$ (2018)

3. G. Chen, M. Hadi, D. Gao, L. Zhao, Construction and Building Materials, 79 (2015)

4. D. Ponjayuthi, K. Vinodh, IJCRR, 8, 12 (2016)

5. H. Chen, J. Zhang, J. Yang, F. Ye, International Journal of Corrosion, 2018 (2018)

6. A. Shetty, K. Venkataramana, I. Gogoi, B. Praveen, Journal of Civil Engineering Research, 2 (2012)

7. A. Almusallam, Construction and building materials, 15 (2001)

8. M. Podskrebko, Strength of materials (Vishaya shkola, Minsk, Russia, 2007)

9. A. Shopov, Proceedings of VSU'2018, 1 (Bulgarian, 2018) 